\title{
Screening and enhancement of the antimicrobial activity of some plant oils using liposomes as nanoscale carrier
}

\author{
Maha G. Haggag ${ }^{1 *}$ (D, Medhat W. Shafaa ${ }^{2}$, Hossam S. Kareem³ ${ }^{3}$ Amir M. El-Gamil ${ }^{4}$ and Hoda H. El-Hendawy ${ }^{4}$
}

\begin{abstract}
Background: Liposomes have the ability to enclose hydrophilic or lipophilic materials. Bioactive macromolecules become more stable when they are entrapped within liposomes resisting environmental changes, allowing maintenance of the antimicrobial molecules and increasing their effectiveness and constancy thus can be used for food preservation. The aim of this study was to screen food samples for microbial contamination and to examine the antimicrobial activity of selected six ready-made plant oils which were; clove, black seed, thyme, garlic, rosemary and green tea against the isolated microbes from food samples and other selected microbes. Also to examine the possible enhancement of the antibacterial property of clove oil and tetracycline versus Escherichia coli when they were encapsulated into distearoyl phosphatidylcholine (DSPC) liposomes as a nanoscale carriers. Results of the antimicrobial action measured by minimum inhibitory concentration revealed that all six oils had antimicrobial action when facing at least one of the tested microbes. However only clove oil could inhibit the growth of all tested microbes. Moreover encapsulation of clove oil into DSPC liposomes enhanced its antibacterial action by 10 times when examined to inhibit the growth of E. coli. Also the antibacterial activity of liposome encapsulated tetracycline was improved by 8 times. Results of characterization of formulated clove oil liposomes by measuring their Zeta potential and their sizes implying that clove oil might be enclosed within the hydrophobic portion of the two layers of the liposome. Analyzing data of Fourier Transform Infrared Spectroscopy showed that clove oil was detected in the interfacial area of the liposome. Analyzing results of Differential scanning calorimetry and measuring phase transitions suggested that liposomes encapsulating clove oil had a membrane fluidization effect.
\end{abstract}

Conclusion: Some plant oils like clove has antimicrobial activity which enhanced with liposomal encapsulation and thus reduces the needed concentration to give the desired actions.

Keywords: Clove, Antimicrobial, Nanoparticles, Liposomes, FTIR, DSC

\section{Background}

Lately there is great concern of using natural alternatives as food preservative to keep food safety, healthy and clear from pathogen contamination A lot of herbs and spices have antimicrobial activity more or less due to holding essential oil constituents which also called volatile oils that embrace different antimicrobial modes of action

\footnotetext{
*Correspondence: mghaggag@gmail.com

${ }^{1}$ Microbiology and Immunology Unit, Allergy Lab, Research Institute

of Ophthalmology (RIO), 2 El Ahram Street, Giza 12557, Egypt

Full list of author information is available at the end of the article
}

(Granados-Chinchilla et al. 2016; Ambrosio et al. 2017). While essential oils have antimicrobial action towards a great variety of pathogens transmitted by food still there is a problem in applying essential oils in food industry because may be more concentration of certain essential oil is obligatory needed to get the same antimicrobial result in food than the concentration required for in-vitro cultural media which may alter taste of food products in an undesirable way (Burt 2004; Songsong 2011).

Liposome is a spherical-shaped envelope synthesized as one or more phospholipid bilayer. Liposomes possess 
unique character being amphiphilic molecule possessing both hydrophilic and lipophilic preference because it is composed of hydrophobic bilayer surrounding hydrophilic inner core which allow solubilization, incorporation and encapsulation of both hydrophobic and hydrophilic drugs (Li et al. 2019). The structure of liposomes is more or less like that of biological membranes and hence liposomes are easily incorporated into cell membranes and adhere to them (Shafaa et al. 2011; Zou et al. 2012).

The advantage of liposome entrapment is stabilizing the encapsulated bioactive macromolecules against various environmental and chemical traumatic factors as exposure to extreme $\mathrm{pH}$ and temperature, enzymatic digestion, presence of reactive chemicals and high ion concentration consequently providing protection, keeping maintenance of the antimicrobial molecules and increasing their effectiveness, reliability and strength hence can be used for food preservation (da Silva Malheiros et al. 2011). Formulation of antibiotics into liposomes prolong the time of antibiotic delivery and thus giving a better chance for dealing with infections that are intracellular. Moreover liposomes can disguise the taste of bitter compounds (Cipolla et al. 2016). However very recently a study made by Hashemzadeh et al (2020) stated that one of the problems in using liposomes as drug carriers is their longterm instability.

The aim of our study was to examine the antimicrobial ability of six plant's oils against selected isolates of Gram-positive and Gram-negative bacteria and yeast and to examine the possible enhancement of the antimicrobial activity of clove oil when loaded into liposomes as nanoscale carriers. Moreover to analyze the formulated clove oil liposomes characterizing their size, size-distribution, thermotropic changes and conformational changes.

\section{Methods}

Food samples and microorganism isolation

The present study involved 45 food samples which were collected from local markets located in Helwan, Cairo Governorate, Egypt. Samples varied form 18 milk samples, 16 yoghurt samples, 5 spices samples, 2 juice samples, 2 processed meat, one mayonnaise sample, and one tahina sample and were screened for microbial contamination by adding $10 \mathrm{~g}$ of tested sample to $90 \mathrm{ml}$ sterile buffered peptone water, mixed well, incubated at $37{ }^{\circ} \mathrm{C}$ for $24 \mathrm{~h}$ then cultured onto Nutrient agar, Blood agar, MacConkey's agar, Eosin methylene blue (EMB) agar, MacConkey sorbitol agar and Sabouraud dextrose agar plates.

Escherichia coli were identified by its characteristic pink colonies on MacConkey's agar. While on EMB agar appeared as green metallic colonies sheen under reflected light (Fig. 1a). Pathogenic E. coli grew as colorless colonies on MacConkey sorbitol agar (Fig. 1b), while non-pathogenic E. coli colonies were red in color. Gram stained films showed G-ve bacilli (Fig. 1c). E. coli was confirmed by giving positive Indole test, positive methyl red and negative Voges-Proskauer (VP) tests. Motility test was positive by hanging drop method.

Salmonella was identified as red colonies with or without black centers on Xylose-Lysine Deoxycholate (XLD) agar (Fig. 2a), isolates have been identified as Gram-negative bacilli (Fig. 2b) which were motile and gave negative indole test.

Candida albicans grew as white colonies on Yeast Extract Glucose Chloramphenicol (YEGC) agar (Fig. 3a). Colonies were identified by Gram stained film that
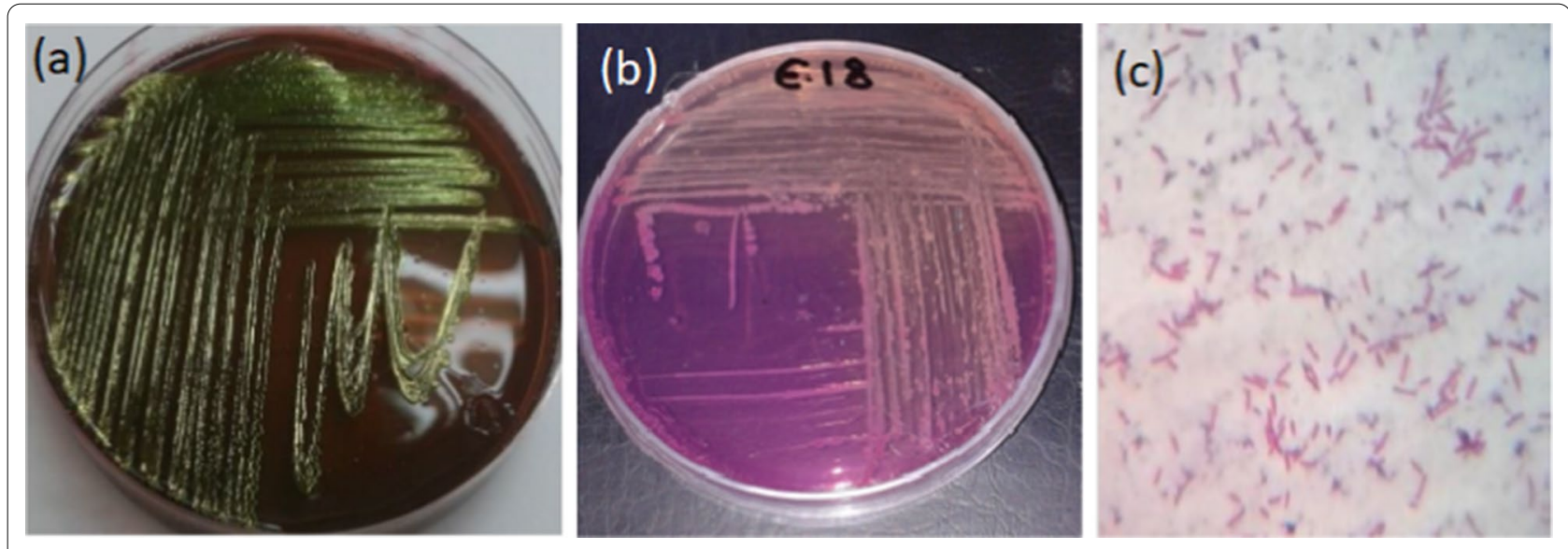

Fig. 1 a E. coli on EMB agar, b Pathgenic E. coli on MacConkey sorbitol agar, c E. coli Gram stained film 

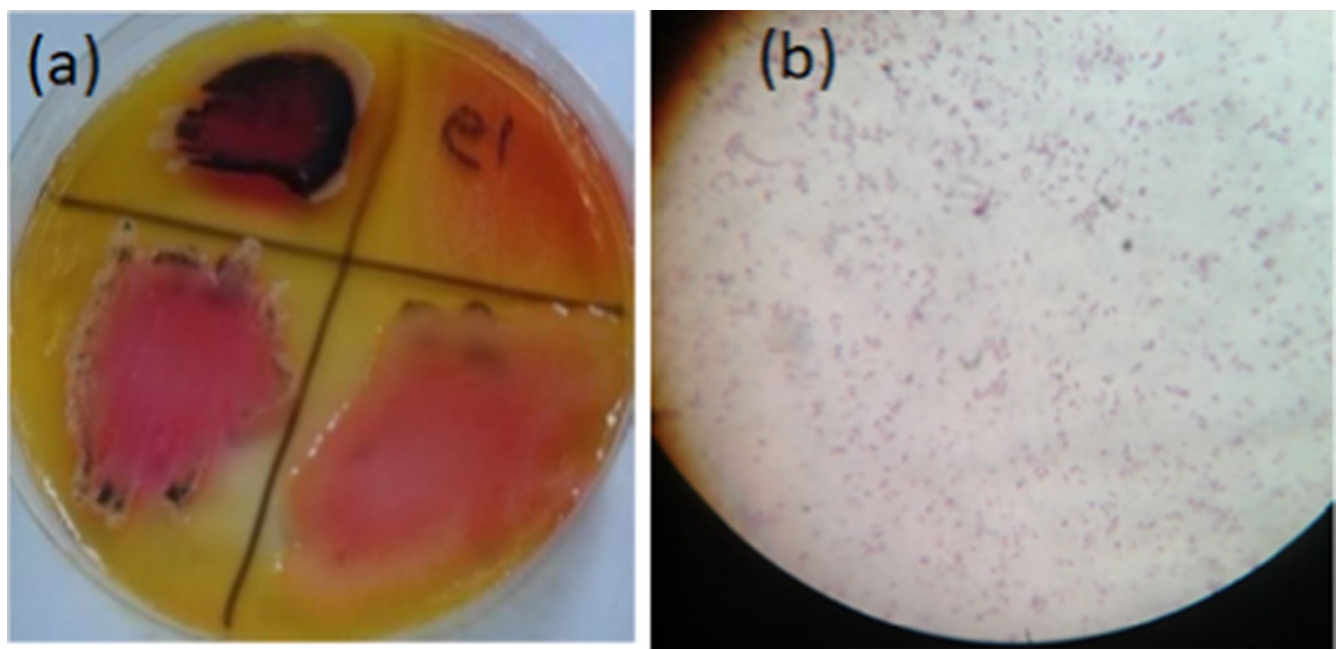

Fig. 2 a Salmonella on XLD agar plate, $\mathbf{b}$ Salmonella Gram stained film
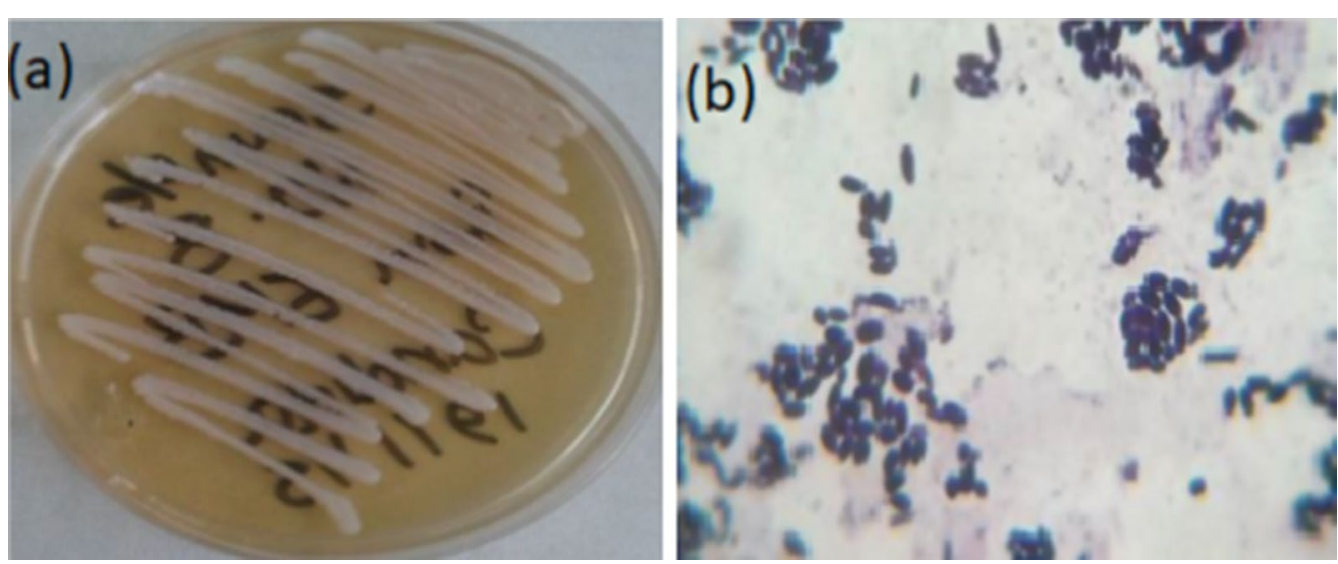

Fig. 3 a Candida albicans on YEGC agar, b C. albicans Gram stained film

showed Gram positive budding oval cells (Fig. 3b) and by positive germ tube test.

\section{Source of microorganisms used in this study}

Escherichia coli, Salmonella and Candida were isolated from the tested food samples showed in (Table 1). Their identification was fully done in the Research Institute of Ophthalmology (RIO) as mentioned above. However Staphylococcus aureus, Klebsiella and Pseudomonas strains were absolutely identified et al. Kasr El-Aini, Cairo University from where they were selected and obtained.

\section{Source of plant oils used in this study}

Six ready-made oils of clove (Syzygium aromaticum) oil, black seed (Nigella sativa) oil, thyme (Thymus vulgaris) oil, garlic (Allium sativum) oil, rosemary (Rosmarinus officinalis) oil and green tea (Camellia sinensis). All test oils were purchased from El-captain company "CAP Pharm" for extracting natural oils, herbs and cosmetics (www.elcaptain.net Info@elcaptain-eg.com). Product descriptions are available in the packages (Fig. 4). Oils were filtered using Nylon Olimpeak ${ }^{\mathrm{TM}}$ Syringe Filter (Teknokroma Italy) $0.45 \mu \mathrm{m}$ and stored in sterile falcon tubes at $4{ }^{\circ} \mathrm{C}$ till use.

\section{Inoculum preparation}

A loopful of the selected microbe was inoculated into $5 \mathrm{ml}$ nutrient broth and incubated at $37^{\circ} \mathrm{C}$ for $24 \mathrm{~h}$, from this $24 \mathrm{~h}$ culture $0.2 \mathrm{ml}$ was taken and added to $19.8 \mathrm{ml}$ sterile nutrient broth and incubated for $3-5 \mathrm{~h}$ to standardize the culture to $10^{6} \mathrm{cfu} / \mathrm{ml}$ according to Abalaka et al. (2012). 
Table 1 Microbes isolated from food samples

\begin{tabular}{|c|c|c|}
\hline Isolate name & Isolate code & Source $^{a}$ \\
\hline \multirow[t]{17}{*}{ E. coli } & $E S 1^{b}$ & Raw milk \\
\hline & $\mathrm{ES} 2^{\mathrm{b}}$ & Yoghurt \\
\hline & ES6 & Raw milk \\
\hline & $\mathrm{ES} 10^{\mathrm{b}}$ & Raw milk \\
\hline & ES12 & Raw milk \\
\hline & $\mathrm{ES} 14^{\mathrm{b}}$ & Raw milk \\
\hline & $\mathrm{ES} 18^{\mathrm{b}}$ & Raw milk \\
\hline & ES24 & Hot chili powder \\
\hline & $\mathrm{ES} 25^{\mathrm{b}}$ & Raw milk \\
\hline & ES27 & Raw milk \\
\hline & $\mathrm{ES} 28^{\mathrm{b}}$ & Yoghurt \\
\hline & ES29 & Raw milk \\
\hline & ES30 & Yoghurt \\
\hline & ES31 & Raw milk \\
\hline & ES34 & Mayonnaise \\
\hline & ES38 & Raw milk \\
\hline & ES42 & Raw milk \\
\hline \multirow[t]{5}{*}{ Salmonella } & SS1 & Raw milk \\
\hline & SS14 & Raw milk \\
\hline & SS18 & Raw milk \\
\hline & SS21 & Hot chili powder \\
\hline & SS31 & Raw milk \\
\hline Candida albicans & CS7 & Yoghurt \\
\hline
\end{tabular}

${ }^{a}$ All samples were collected from local markets, Helwan area

${ }^{b}$ Pathogenic E. coli isolates

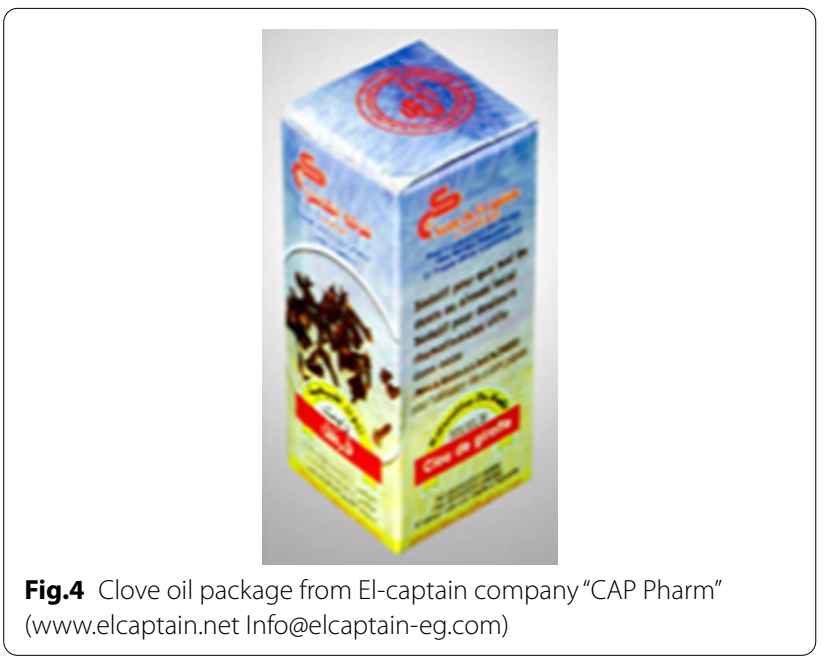

\section{Antimicrobial activity assay}

The antimicrobial activities of plant oils were measured using: The well diffusion method as described by the British Pharmacopoeia (2010). After sterilization of nutrient agar medium, it was left to cool to $48{ }^{\circ} \mathrm{C}$ then $1 \mathrm{ml}$ of the bacterial suspension $\left(10^{6} \mathrm{cfu}\right)$ was added to $100 \mathrm{ml}$ nutrient agar medium and thoroughly mixed by rotary motion of the flasks. Immediately the seeded medium was poured into Petri dishes. A sterile cork borer $6 \mathrm{~mm}$ diameter was used to perform wells in each plate then $100 \mu \mathrm{l}$ of sterile oil extracts were applied to each well and plates were kept on bench for one hour at room temperature to permit diffusion of the extract before incubation at $37^{\circ} \mathrm{C}$ for $24 \mathrm{~h}$. Finally measuring the diameter of inhibition zones in millimeters was done (Fig. 5).

\section{MIC and MBC determination}

In the present study MIC assay was done by broth macrodilution method by inoculating the organism into small microcentrifuge tubes containing two-fold dilutions of each antimicrobial agent (tested oil extract). After incubation at $35^{\circ} \mathrm{C}$ for $24 \mathrm{~h}$ the lowest concentration of the antimicrobial agent that prevents visible growth of the organism is the MIC (CLSI 2012). MIC is considered as the logarithmic difference in population (Log DP) which is calculated by the following equation: $\log \mathrm{DP}=\log$ $(N / \mathrm{No})=(\log N)-(\log$ No) Where $N$ is the bacterial population after incubation for $24 \mathrm{~h}$ and No is the initial population. MIC is considered as the lowest concentration preventing visible bacterial growth $(\log \mathrm{DP} \leq 0)$. The minimum bactericidal concentration $(\mathrm{MBC})$ is defined as the concentration where $99.9 \%$ or more of the initial inoculums are killed (Log DP $\leq-3$ ) Pei et al. (2009).

\section{Preparation of liposomes}

Liposomes were prepared using high purity distearoyl phosphatidylcholine (DSPC), with a molecular weight of $790.161 \mathrm{~g} / \mathrm{mol}$ (99\% pure), Tris buffer extra pure 99\% with a molecular weight of $121.14 \mathrm{~g} / \mathrm{mol}$ (LOBA CHEMIE, INDIA). DSPC: tested extract of clove oil or tetracycline at molar ratio 7:4 were used to prepare neutral multilamellar vesicles (MLVs) using the method described by Shafaa et al. (2011).

Required mass of DSPC and tested extract of clove oil were calculated based on the molecular weight of each and selected molar ratio thus to prepare $5 \mathrm{ml}$ of $1 \mathrm{mg} / \mathrm{ml}$ liposomal clove oil; $33.62 \mathrm{mg}$ of DSPC were mixed with $5 \mathrm{mg}$ clove then transferred to $50 \mathrm{ml}$ round bottom flask, $10 \mathrm{ml}$ of absolute ethyl alcohol was added and flask was shacked to dissolve all lipids in the solvent. Using rotary evaporator under vacuum to evaporate the solvent with the aid of a suitable flow of nitrogen to obtain a film of deposited lipids onto the wall and the bottom of the flask. The solvent was removed slowly to permit appropriate integration of components. To ensure complete evaporation of the solvent the flask was kept under vacuum for $12 \mathrm{~h}$ because the presence any traces of solvent is harmful for the assembly of domains (Ibrahim et al. 2011) Based on desired extract 

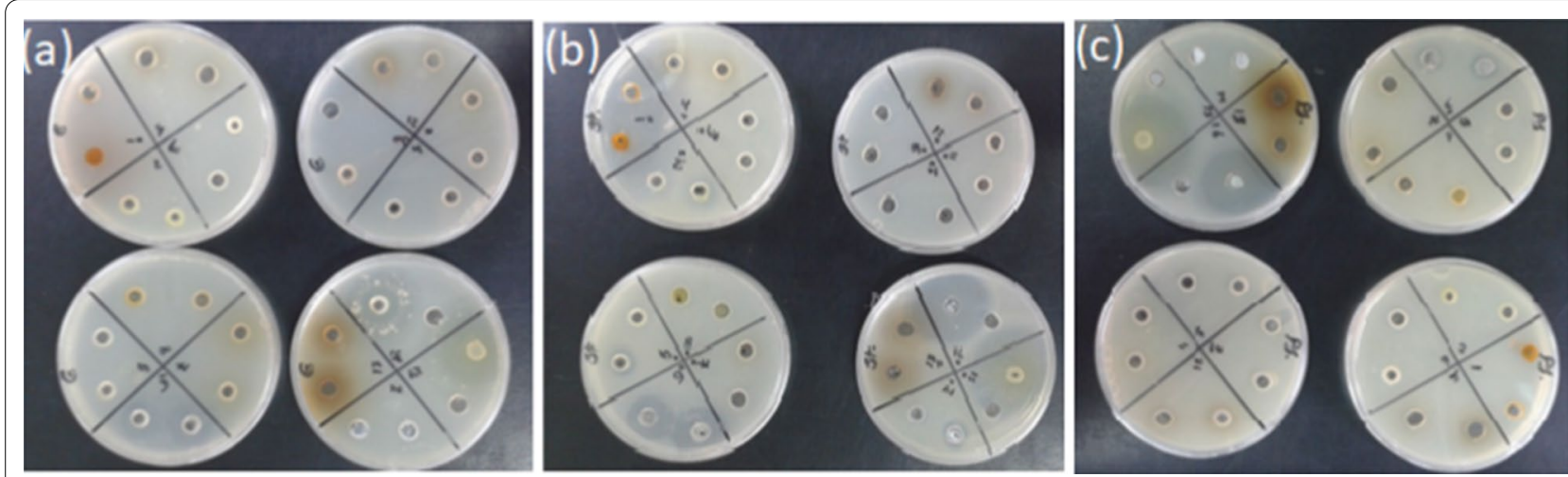

Fig. 5 Antimicrobial activity by well diffusion method for a E. coli, b S. aureus, c pseudomonas

final concentration add suitable amount in milliliter of buffer $10 \mathrm{mM}$ Trizma adjusted to $\mathrm{pH} 7$. Mechanical shaking of the flask was done for $1 \mathrm{~h}$ at $45^{\circ} \mathrm{C}$. Then the flask was thoroughly flashed with nitrogen stream and immediately closed.

Liposomal entrapment of tetracycline (source of tetracycline was the Arab Drug Company ADCO, Egypt) was done parallel to liposomal clove oil encapsulation thus to prepare $5 \mathrm{ml}$ of $4 \mathrm{mg} / \mathrm{ml}$ of liposomal tetracycline; $15.56 \mathrm{mg}$ of DSPC were mixed with $5 \mathrm{mg}$ tetracycline in ethanol and evaporated to form a thin dried film under the same condition as before. The hydration of the dry lipid thin film was achieved with Tris base buffer at tetracycline to lipid molar ratio $=4: 7$. Control empty liposomes were made by only fractions of DSPC. Storage of liposomal dispersion at $4{ }^{\circ} \mathrm{C}$ until use ((Masserini et al. 2002; Shafaa et al. 2011; Jurado et al. 2016; Chen et al. 2016).

\section{Characterization of prepared liposomes}

Prepared liposomes were characterized in terms of encapsulation efficacy, zeta potential, vesicle size, morphology, Fourier transform infrared spectroscopy, and differential scanning calorimetry analysis.

Entrapment efficiency (EE) of liposomes was assessed by measuring the amount of free un-encapsulated clove through UV-spectrophotometric technique at $237 \mathrm{~nm}$ (resonance absorption peak of clove oil) with reference to a previously constructed calibration curve.

$E E$ is the percentage of the drug that is successfully entrapped into the nanoparticles. It was calculated by using the following equation:

$$
\mathrm{EE}=\frac{(\mathrm{Ci}-\mathrm{Cf})}{\mathrm{Ci}} \times 100
$$

where $\mathrm{Ci}$ is the concentration of the initial clove added (also called total conc $\mathrm{Ct}$ ) and $\mathrm{Cf}$ is the concentration of free clove (Ibrahim et al. 2011; Chen et al. 2016).
Zeta potential is the outcome of all charges present on the surface of any material when distributed into dispersion medium. It is a very reliable parameter that reflect the degree of electrostatic repulsion between the charged particles in the dispersion and hence it is a clue for stability of colloidal dispersions and its value allowing to access quality control and improving product performance (Perrotta et al. 2016). All samples were diluted in the ratio $1: 10(\mathrm{v} / \mathrm{v})$ with double distilled water and the mean standard deviation of three determinations were reported. Evaluation of the zeta potential of liposomal preparation was done by Laser Zeta-meter (Nanotrac Wave II, Microtrac, USA) by Nawah Scientific according to Mozafari et al (2014).

\section{Morphological characterization}

Liposome suspensions were imaged, using a transmission electron microscope (TEM). Dilution of samples 10 times was done using distilled water. Equivalent volumes of both ammonium molybdate $2 \%$ solution and the diluted sample were mixed and left for $3 \mathrm{~min}$ at room temperature. A drop of this mixture solution was placed on a copper mesh for 5 min then by using filter papers the excess liquid was drawn off. Examination of the mesh was done using JEOL 1200-EX II TEM (JEOL Ltd, Tokyo, Japan) in the Central Lab at Ain Shams University according to Mozafari et al (2014).

Fourier Transform Infrared Spectroscopy (FTIR) spectra of lyophilized blank, and clove oil encapsulated into liposomes were measured from 400 to $4000 \mathrm{~cm}^{-1}$ by FT-IR spectrometer 4100 (JASCO, Japan), was done in the Micro Analytical Center at Cairo University.

\section{Differential scanning calorimetry (DSC) analysis}

The thermal behavior was studied by (DSC-60, Shimadzu, Japan) calibration was done using indium to examine the thermal performance of lyophilized samples of empty 
and clove-loaded multilamellar liposomes. Samples of $5 \mathrm{mg}$ was placed in standard aluminum pans and sealed for analysis. The temperature range of $2-250{ }^{\circ} \mathrm{C}$ was covered by the thermogram for each sample at a scanning rate of $10{ }^{\circ} \mathrm{C} / \mathrm{min}$ which was done in the Micro Analytical Center at Cairo University.

\section{Results}

In the present study screening of 45 different food samples for microbial contamination revealed the presence of 17 E. coli isolates, 5 Salmonella isolates and one C. albicans isolate.

Results of screening of the antimicrobial activity of six tested plant oils against six microbial isolates including the three microbes isolated from food samples measured by well diffusion method (Table 2) and by minimal inhibitory concentration (MIC) (Table 3).

Results revealed clove was the only plant oil that showed antimicrobial activity against all the tested isolates and hence it was selected for testing the effect of liposomal encapsulation.

Results of antimicrobial activity enhancement by liposomal loading:

According to the equation mentioned earlier $\mathrm{MBC}$ is when Log DP $\leq-3$ Pei et al. (2009) therefore from the bar chart (Fig. 6a, b) the value of Log DP of E. coli as -4.30 represented the $\mathrm{MBC}$ of clove oil which reached at $5 \mathrm{mg} / \mathrm{ml}$ meanwhile this value could be reached with liposomal clove concentration of $0.5 \mathrm{mg} / \mathrm{ml}$ only, and hence the antimicrobial activity of clove oil was enhanced by 10 times when clove oil was carried on liposomes $(5 / 0.5=10)$. Also encapsulation of tetracycline into liposomes increased its antimicrobial activity as shown in (Fig. 7a, b) where Log DP of E. coli as - 8.04 represented the MBC of unloaded tetracycline which reached at $1 \mathrm{mg} / \mathrm{ml}$ while $\operatorname{LogDP}$ as -5.04 represented $\mathrm{MBC}$ of liposomal tetracycline which reached at $0.125 \mathrm{mg} /$ $\mathrm{ml}$. Thus the antimicrobial activity of tetracycline was enhanced 8 times when tetracycline was carried on liposomes $(1 / 0.125=8)$.

\section{Liposomes characterization}

Encapsulation efficiency (EE) of clove was measured to be $22.068 \%$. The absorbance at different concentration of clove oil was measured using a UV-Vis spectrophotometer at $237 \mathrm{~nm}$. A standard curve was made by plotting absorbance against concentration. The concentration of the non-encapsulated clove oil in the supernatant was measured using this curve. The encapsulation efficiency was calculated as the mass ratio of the amount of the clove oil entrapped into liposomes and this calculated ratio was used in the liposome preparation (Fig. 8).

Zeta potential analyzer was used to determine the electro-kinetic surface potential for empty and

Table 2 The antimicrobial activity of studied plant oils against different microbial isolates using well diffusion method

\begin{tabular}{lllllll}
\hline Plant name & \multicolumn{2}{l}{ Diameters of inhibition zones in $\mathbf{~ m m}$} & & \\
\cline { 2 - 7 } & Candida & E. Coli & Salmonella & S. aureus & Klebsiella & Pseudomonas \\
\hline Clove & $5 \mathrm{~mm}$ & $7 \mathrm{~mm}$ & $4 \mathrm{~mm}$ & $8 \mathrm{~mm}$ & $6 \mathrm{~mm}$ & $3 \mathrm{~mm}$ \\
Black seed & 0 & 0 & 0 & 13 & $28 \mathrm{~mm}$ & 0 \\
Rosemary & 0 & 0 & 0 & $3 \mathrm{~mm}$ & $3 \mathrm{~mm}$ & 0 \\
Green tea & $2 \mathrm{~mm}$ & $2 \mathrm{~mm}$ & 0 & 0 & 0 & 0 \\
Thyme & 0 & 0 & 0 & 0 & 0 & 0 \\
Garlic & 0 & 0 & 0 & 0 & 0 & 0 \\
\hline
\end{tabular}

Table 3 The antimicrobial activity of studied plant oils against different microbial isolates measured by the minimal inhibitory concentration (MIC)

\begin{tabular}{|c|c|c|c|c|c|c|}
\hline \multirow[t]{2}{*}{ Plant name } & \multicolumn{6}{|c|}{ MIC in $\mathrm{mg} / \mathrm{ml}$} \\
\hline & Candida & E. Coli & Salmonella & S. aureus & Klebsiella & Pseudomonas \\
\hline Clove & 28.4 & 28.4 & 28.4 & 113.4 & 28.4 & 56.7 \\
\hline Black seed & 0 & 0 & 0 & 28.5 & 28.5 & 0 \\
\hline Rosemary & 0 & 0 & 0 & 189.6 & 47.4 & 0 \\
\hline Green tea & 231.4 & 115.7 & 0 & 115.7 & 0 & 0 \\
\hline Thyme & 0 & 0 & 0 & 0 & 94.2 & 0 \\
\hline Garlic & 0 & 413.5 & 413.5 & 0 & 0 & 0 \\
\hline
\end{tabular}



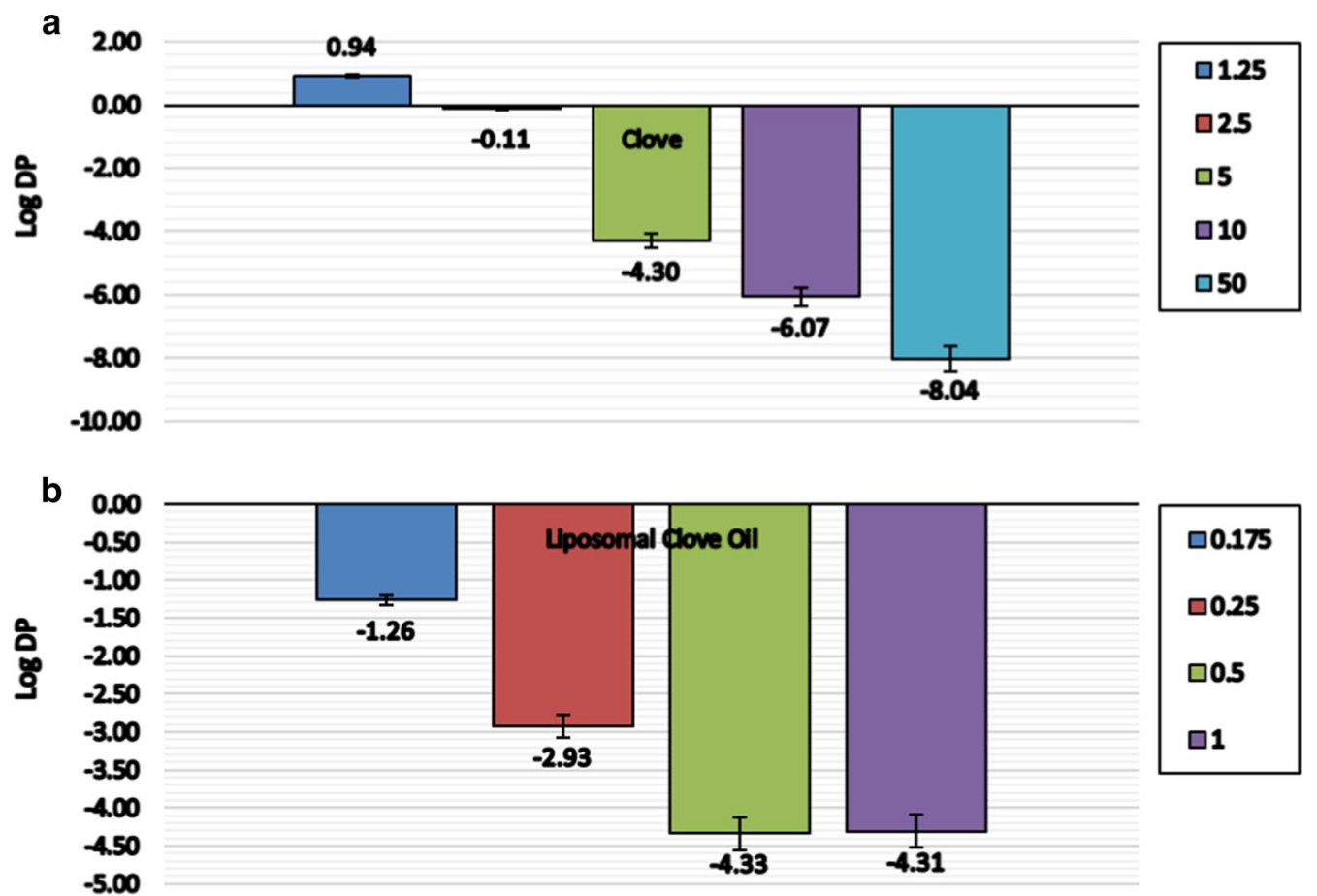

Fig. 6 Effect of clove oil against E. coli before and after its liposomal encapsulation. a Effect of clove oil against E. coli. b Effect of liposomal clove oil against E. coli

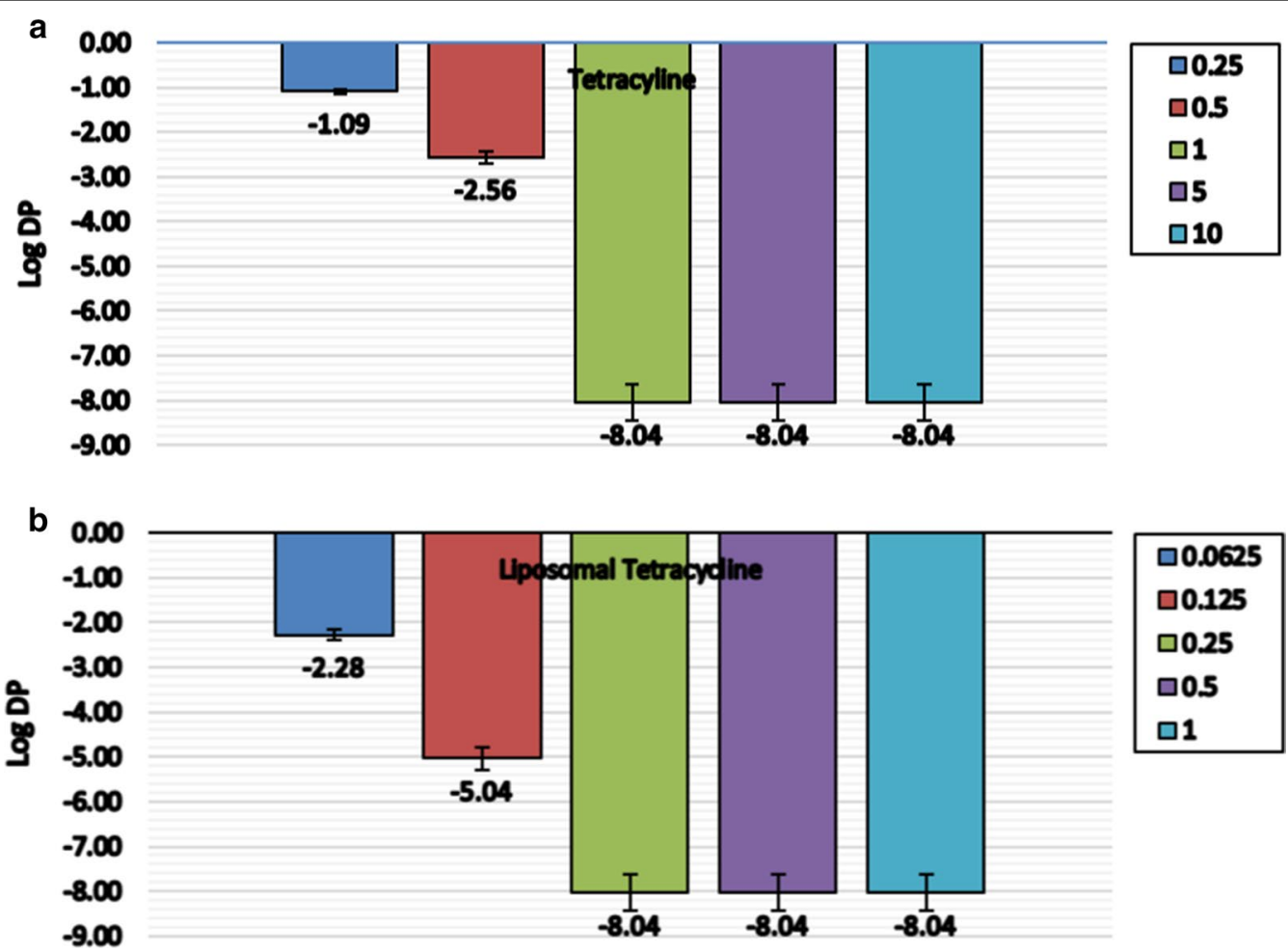

Fig. 7 Effect of tetracycline against E. coli. Before and after its liposomal encapsulation. a Effect of tetracycline against E. coli. b Effect of liposomal tetracycline against $E$. coli 
encapsulated liposomes and showed that clove encapsulation increased in zeta potential about fivefold compared to empty liposomes. DSPC liposomes and clove loaded liposomes zeta potential were measured to be $-18.6 \pm 25.0$ and $-117.5 \pm 85.2 \mathrm{mV}$, respectively.

The morphology and size of blank and clove oil encapsulated liposomes were examined by TEM images that showed well dispersed and not aggregated round shaped empty and encapsulated vesicles had a diameter around $232.33 \pm 10.63 \mathrm{~nm}$ and $979 \pm 27 \mathrm{~nm}$, respectively (Fig. 9).

A stack plot of the FTIR spectra of pure lyophilized DSPC liposomes compared with clove oil loaded DSPC liposomal sample in the region $400-4000 \mathrm{~mm}$ are presented in (Fig. 10). FTIR spectra of blank lyophilized DSPC liposomes were analyzed. Information on the order/disorder state by means of acyl chain flexibility of the lipid membranes was presented by symmetric, and anti-symmetric stretching vibration of the $\mathrm{CH}_{2}$ in the acyl chain were located at wave numbers 2851.24 , and $2919.7 \mathrm{~mm}$ respectively. $\mathrm{CH}_{2}$ bending vibration peak was located at $1469.49 \mathrm{~mm}$, while symmetric, and antisymmetric $\mathrm{PO}_{2}{ }^{-}$stretching vibrations were located at 1095.37, and $1247.72 \mathrm{~mm}$, respectively. $\mathrm{OH}$ stretching, and bending vibrations were observed at wave numbers 3422.06 , and $1636.30 \mathrm{~mm}$, respectively. Carbonyl stretching vibrations $\mathrm{C}=\mathrm{O}$ was located at $1738.51 \mathrm{~mm}$.

Amide I band due to $\mathrm{C}=\mathrm{O}$ stretching vibration of the peptide group in $1636.30 \mathrm{~mm}(\mathrm{CH} 3)_{3} \mathrm{~N}^{+}$asymmetric stretching in $970.019 \mathrm{~mm}$. While both Aliphatic phosphates $\mathrm{P}-\mathrm{O}-\mathrm{C}$ stretch, and $(\mathrm{CH} 3)_{3} \mathrm{~N}^{+}$symmetric bending spectra were not detected.
FTIR spectra of lyophilized clove oil loaded DSPC liposomes showed no change in both symmetric, and anti-symmetric stretching vibration of the $\mathrm{CH}_{2}$ in the acyl chain to be 2851.24 , and $2919.7 \mathrm{~mm}$ respectively. Reduction in wave number values were detected in case of $\mathrm{CH}_{2}$ bending vibration, symmetric $\mathrm{PO}_{2}$ stretching vibration, and amide $\mathrm{I}$ band due to $\mathrm{C}=\mathrm{O}$ stretching vibration of the peptide group to be 1468.53, 1093.44, 1635.34 , and $1635.34 \mathrm{~mm}$ respectively. Wave number values increased in case of Anti-symmetric $\mathrm{PO}_{2}$ stretching vibration, $\mathrm{OH}$ stretching vibration, Carbonyl stretching vibrations $\mathrm{C}=\mathrm{O}$, and $(\mathrm{CH} 3)_{3} \mathrm{~N}^{+}$asymmetric stretching to be $1249.65,3429.78,1739.48$, and $970.983 \mathrm{~mm}$ respectively. While Amide II band due to $\mathrm{N}-\mathrm{H}$ bending with contribution of $\mathrm{C}-\mathrm{N}$ stretching vibrations was not detected.

DSC analysis of lyophilized pure DSPC and clove loaded DSPC vesicles were presented in DSC thermograms (Fig. 11). Upon dehydration, pure DSPC vesicles showed a major endothermic peak at $79{ }^{\circ} \mathrm{C}$ and the pretransition temperature was around $64{ }^{\circ} \mathrm{C}$. Whereas lyophilized clove oil loaded liposomes exhibited noticeable broadening and a decrease in temperature to $72{ }^{\circ} \mathrm{C}$ and the pre-transition temperature also shifted from 64 to $54{ }^{\circ} \mathrm{C}$.

\section{Discussion}

In the present study screening of 45 different food samples varied form milk, yogurt, cheese, spices, processed meat, and juice were screened for microbial contamination revealed 17 samples were contaminated with $E$. coli $(37.8 \%)$ and 5 food samples were contaminated with

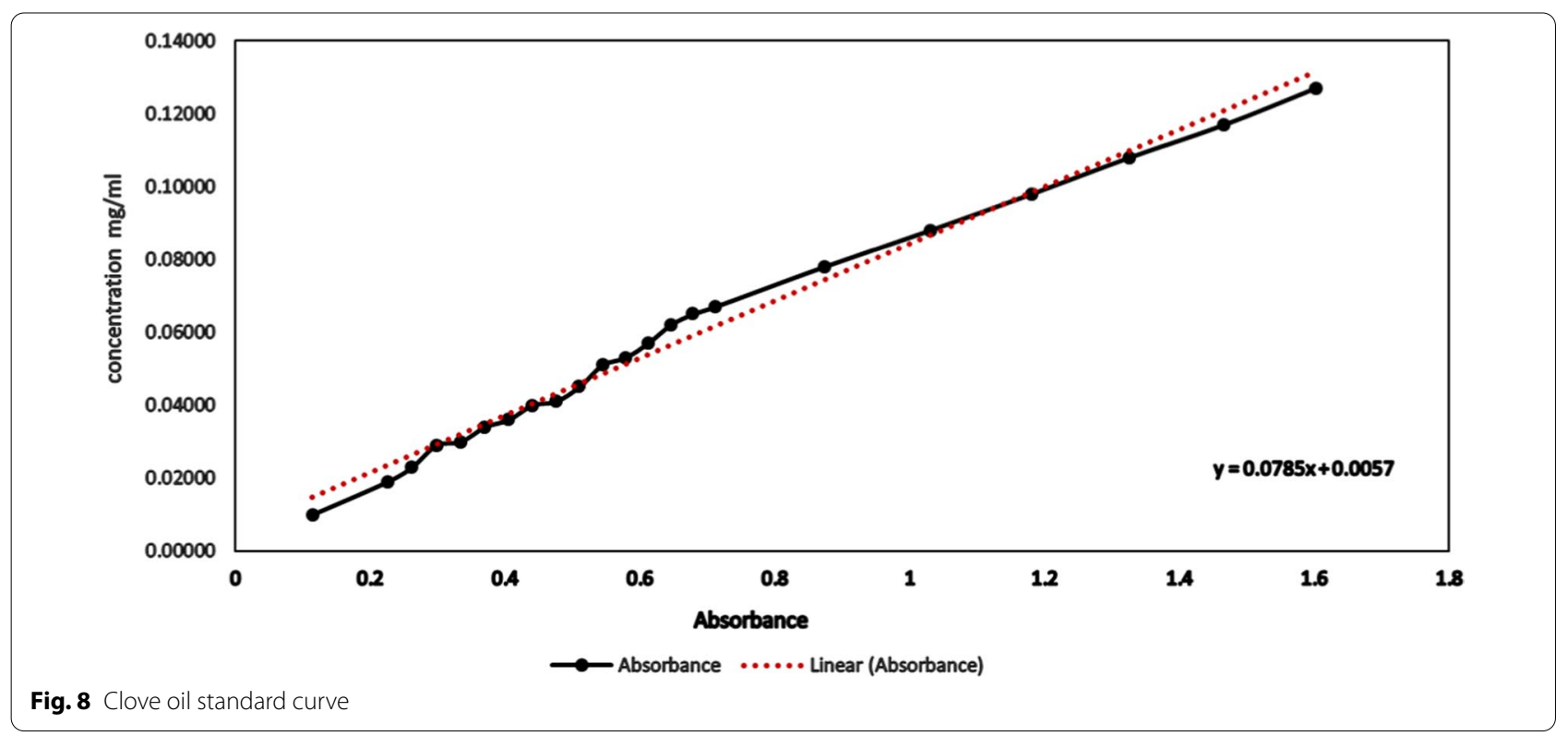


a

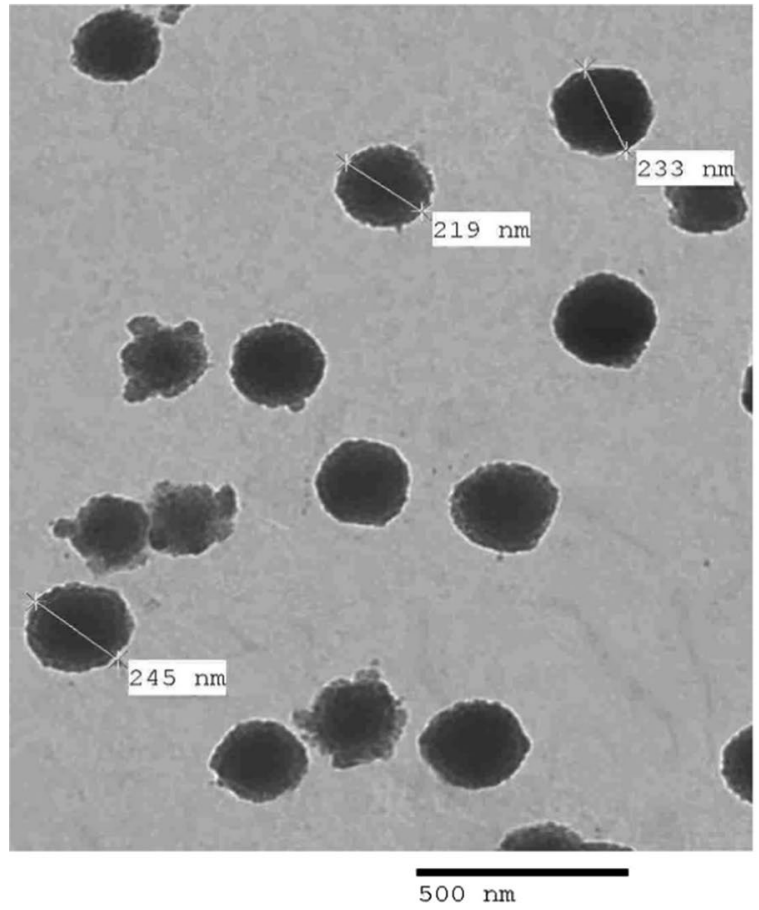

b

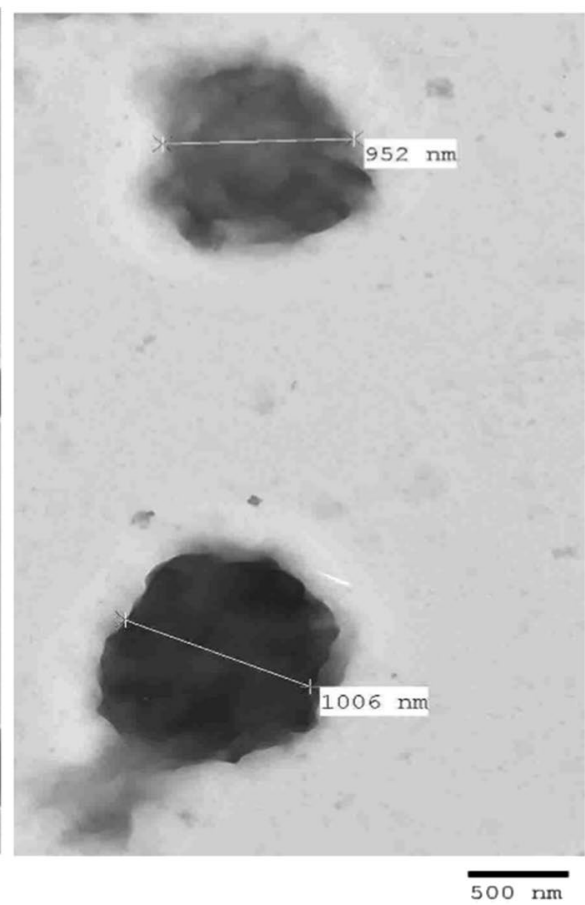

Fig. 9 TEM micrograph for blank and clove liposomes. a TEM micrograph for blank liposomes (magnification ×5400). b TEM micrograph for clove liposomes (magnification × 2700)

Salmonella (11.1\%) and only one food sample was contaminated with $C$. albicans. Both bacteria were found mainly in milk and milk goods.

Oliver et al (2009) reviewed food safety and its hazards joined to utilization of unprocessed milk and showed that E. coli and salmonella were the most common contaminants of milk and its products.

The mechanism by which essential oils can combat microbes has not been fully explained. Essential oils do not aim a specific target in the cell nevertheless they targets many goals in the cell. When essential oils enter the cell wall penetrating the cytoplasmic membrane of pathogens they cause structure disruption of their polysaccharides, phospholipids and fatty acids layers increasing their permeability (Chaieb et al. 2007; Bakkali et al. 2008). This increased permeability is accompanied by ions depletion, inhibition of the proton pump, decreased ATP synthesis, inhibition of respiration and hence cell death of the pathogen whether it is $\mathrm{G}+$ ve or $\mathrm{G}$ - ve bacteria (Nazzaro et al. 2013; Mohammed et al. 2019).

Clove is the common name of Syzygium aromaticum family Myrtaceae. Eugenol is the main component of clove's essential oil which owes its antibacterial effect by making the cell membrane more permeable and interrelate with its proteins and that was proved by many different studies to be due to increased movement of potassium and ATP out of bacterial cells (Hyldgaard et al. 2012). Moreover when clove essential oil enters the bacterial cell it inhibits DNA synthesis and proteins necessary for bacterial growth implying damage at the molecular level rather than only physical damage (Xu et al. 2016).

In the present study results of screening of the antimicrobial activity of six ready-made oils: clove (Syzygium aromaticum) oil, black seed (Nigella sativa) oil, thyme (Thymus vulgaris) oil, garlic (Allium sativum) oil, rosemary (Rosmarinus officinalis) oil and green tea (Camellia sinensis) measured by well diffusion method against six microbial isolates: Escherichia coli, Salmonella typhi, Candida albicans, Staphylococcus aureus, Klebsiella and Pseudomonas proved that all tested oils had antimicrobial tendency when facing at least one of the above mentioned six microbes. However clove oil was the only one that has antimicrobial affinity against all of the tested microbes.

Nzeako et al (2006) in their study reported that $C$. albicans was the most sensitive organism to the antimicrobial activity of clove oil and thyme than S. aureus, Pseudomonas aeruginosa, E. coli and Salmonella species. They also concluded that whatever the country of origin of herbs is had no effect on their antibacterial benefit. However Ncube et al. (2008) concluded that the variety 


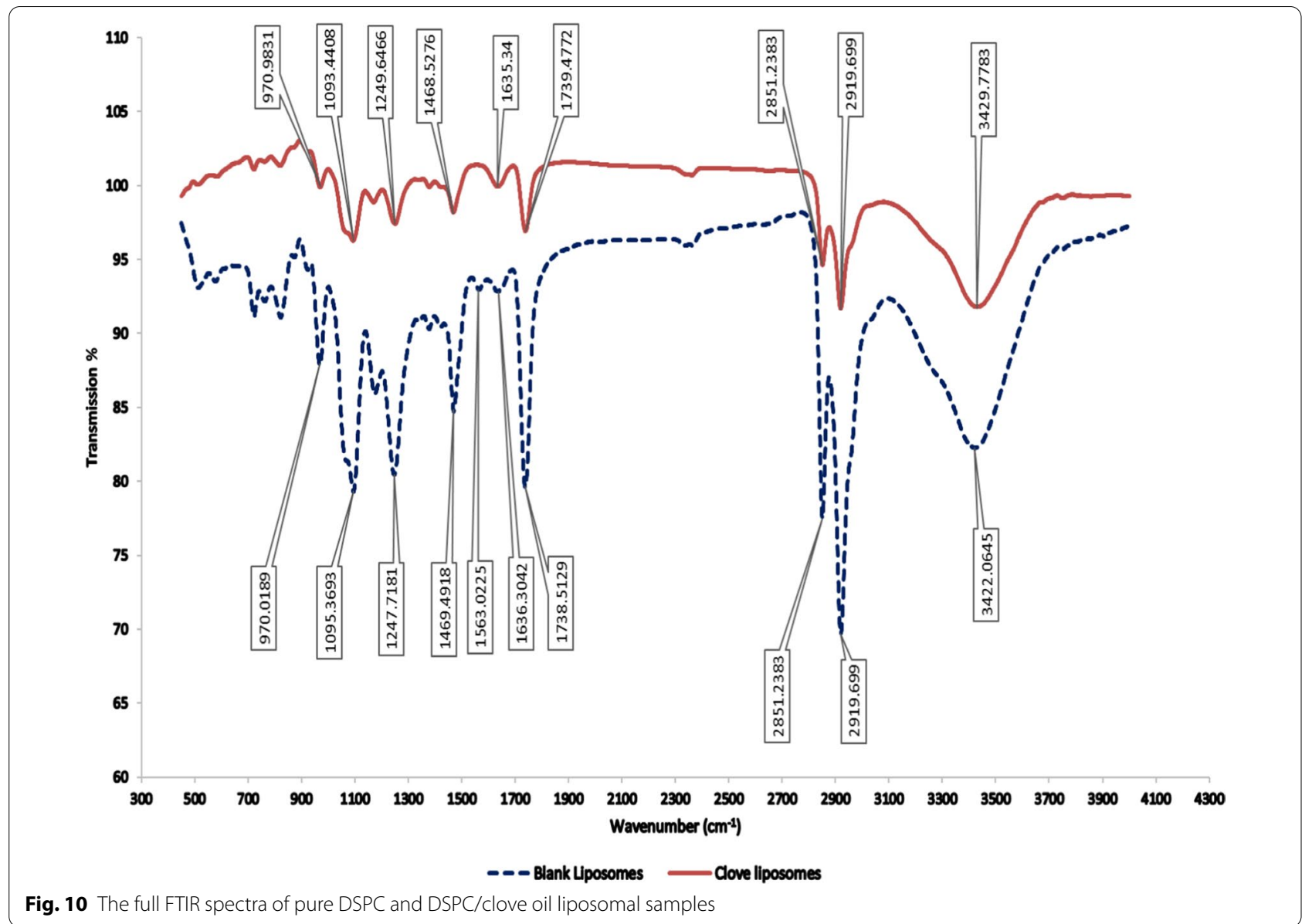

of the plant parts used in extraction as well as the extraction method led to various antimicrobial effects.

The antibacterial effects of clove oil and rosemary oil were among many other oils studied by Prabuseenivasan

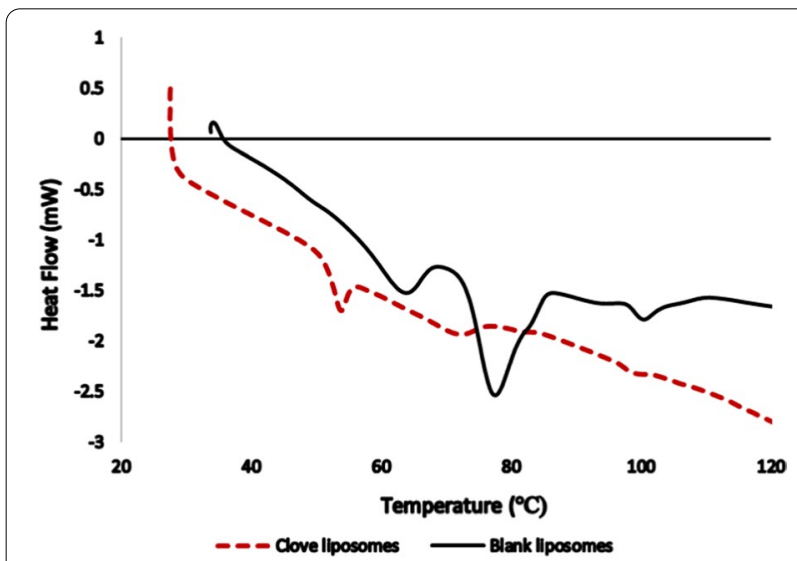

Fig. 11 DSC thermograms for DSPC Liposomes in the absence and presence of clove oil et al (2006) against S. aureus, E. coli, K. pneumoniae, $P$. aeruginosa and two other bacteria. Their results showed inhibition zone rang for clove oil from 16 to $17 \mathrm{~mm}$ against all four bacteria and that of rosemary was 12 to $23 \mathrm{~mm}$ also against the four bacteria. These results of clove oil and rosemary oil were greater than the results in this study.

Regarding the antibacterial activity of black seed (Nigella sativa) oil, quite large number of studies have been established by various researchers to explore the pharmacological action of black seed oil as stated by Safhia et al. (2014) the black seed oil commercially available was selected for their study without dilution or chemical alteration, Staphylococcus aureus, Escherichia coli and Klebsiella planticola were among other tested bacteria. Inhibition zone of $S$. aureus was $14 \mathrm{~mm}$ which was the most significant result when compared to Ciprofloxacin disc $(5 \mu \mathrm{g} / \mathrm{disc})$ while that of $E$. coli was non-significant however Klebsiella showed no zone of inhibition. The result in the present study as $13 \mathrm{~mm}$ agrees with their results regarding $S$. aureus only. Approximate results to ours were reported by Mohammed et al. (2019) 
concerning the antibacterial action of black seed (Nigella sativa) oil towards Staphylococcus aureus where inhibition zone diameter was $11.5 \mathrm{~mm}$. They explained the antimicrobial effect of black seed oil to be attributed to thymoquinone which is a volatile oil of these seeds that characteriscally has free rotation bonds in the $\mathrm{CH}_{3}$ group which qualify thymoquinone and other constituents of black seed oil to change their shapes according to the available bacteria and easily cross or enter their boundary leading to their death. While earlier Bakathir and Abbas (2011) explained the positive inhibition of black seed to $S$. aureus may be due to thymoquinone and melanin.

Various techniques for encapsulation were used in food industry to deliver some active compounds such as additives, colors, enzymes and preservatives. However their incorporation into liposomes as nanoparticles is distinguished by the unique liposomal characteristic which is the capacity to entrap both hydrophobic and hydrophilic particles. Liposomes also have the advantages of being biocompatible, biodegradable, non toxic and non immunogenic. For all these reasons liposome nanocapsules have considered as one of the tempting persuasive package material in pharmaceutical and food manufacturing (Ghorbanzade et al. 2017; Corrêa et al. 2019).

A comparative study was done by Anderson and Omri (2004) between three types of formulated liposomes considering encapsulation efficacy as a crucial factor in liposome parameters they reported that DSPC liposomes showed the greatest encapsulation efficiency between the three formulations which might be due to their shorter hydrocarbon chain $\left(C_{14}\right)$ DSPC liposomes had also shown the most drug retention.

Regarding measurement of zeta potentials which is one of the standard characterization techniques to evaluate the final conclusion of nanoparticle surface charge character whether cationic, anionic or neutral character (Smith et al. 2017). That was clearly explained by Paolino et al. (2006) and Elmeshad et al. (2013) who stated that the magnitude of zeta potential is the clue for the potential stability of nanoliposomes composition and estimation of in-vivo fate of these nanocarriers. Because when zeta potential increases it leads to more repulsion between particles resulting in more stable colloidal dispersion. In other words when all particles in suspension have a large negative or positive zeta potential, then the particles have a propensity to repel each other leaving no chance for their aggregation together.

In the present study blank DSPC liposomes showed negative zeta potential as $(-18.6 \pm 25.0 \mathrm{mV})$ in accordance with Makino et al (1991).

Results reported by Elmeshad et al. (2013) stated that the nanoliposomal formulations had average zeta potential with a range from $23.3 \pm 1.2$ to $35.8 \pm 0.3 \mathrm{mV}$.
In the present study clove loaded liposomes had higher negative zeta potential $(-117.5 \pm 85.2 \mathrm{mV})$ which may be explained by the presence of hydroxyl $\left(\mathrm{OH}^{-}\right)$group on the clove surface liposomes that might be physically associated by the surface without upsetting the packing membrane suggesting that clove oil might be caught in the hydrophobic fraction of the liposomal bilayer. The presence of Hydroxyl $\left(\mathrm{OH}^{-}\right)$group on the clove surface with more negative zeta potential acted as stabilizing material.

In the present study TEM images showed well dispersed and not aggregated round shaped empty and encapsulated vesicles had a diameter around $232.33 \pm 10.63 \mathrm{~nm}$ and $979 \pm 27 \mathrm{~nm}$ respectively. The large size of clove oil encapsulated liposome might be explained considering the existence of phospholipid $\mathrm{PO}_{2}{ }^{-}$group in the polar head of DSPC liposomes might prevent the clove hydroxyl $\left(\mathrm{OH}^{-}\right)$group from getting close to the $\mathrm{PO}_{2}{ }^{-}$group because of the electrostatic repulsive force between the DSPC $\mathrm{PO}_{2}{ }^{-}$group and the clove hydroxyl $\left(\mathrm{OH}^{-}\right)$group thus weakening the interactions between phospholipid $\mathrm{PO}_{2}{ }^{-}$and clove hydroxyl $\left(\mathrm{OH}^{-}\right)$group. The presence of hydroxyl $\left(\mathrm{OH}^{-}\right)$group on the clove surface liposomes that might be physically associated by the surface without upsetting the packing membrane suggesting that clove oil might be caught in the hydrophobic fraction of the liposomal bilayer. These findings show that the presence of clove oil in liposomes increased the spacing between the adjacent bilayer, resulting in larger-sized liposomes compared to the control empty liposomes.

While results reported by Elmeshad et al. (2013) showed the opposite as the loaded nanoliposomes was possessing the minimum vesicle size $(532 \pm 26 \mathrm{~nm})$ which was a surprising finding and was explained by the hydrophilic nature of the entrapped material in their study which lead to its segregation inside the aqueous phase rather than being trapped within the hydrophobic part of the liposomes.

FTIR studies were done to examine the effect of clove oil on the DSPC liposomes. The spectrum of the DSPC liposomes (Fig. 5) exhibited the major characteristic bands demonstrating the symmetric and anti-symmetric stretching vibrations of the $\mathrm{CH}_{2}$ inside the acyl chain (2850 and $2920 \mathrm{~cm}^{-1}$ respectively) the $\mathrm{OH}$ stretching and bending vibrations ( 3470 and $1640 \mathrm{~cm}^{-1}$ respectively) the carbonyl stretching vibration $\mathrm{C}=\mathrm{O}\left(1734 \mathrm{~cm}^{-1}\right)$ the $\mathrm{CH}_{2}$ bending vibration $\mathrm{CH}_{2}\left(1470 \mathrm{~cm}^{-1}\right)$ and the symmetric and anti-symmetric $\mathrm{PO}_{2}^{-}$stretching vibrations (1090 and $1220 \mathrm{~cm}^{-1}$ respectively) same results were reported and published in a previous study by one of our authors with Mady et al. (2012) also these results are in accordance with Mady and Elshemey (2011). 
In the present study incorporation of clove oil into the DSPC liposomes showed no significant variation in the frequency of the symmetric and anti-symmetric $\mathrm{CH}_{2}$ stretching bands within the acyl chain observed implying that clove oil does not alter the number of gauche conformers. While FTIR measurements reported by Mady et al (2011) revealed that gold nanoparticles made significant alterations in the frequency of the $\mathrm{CH}_{2}$ stretching bands suggesting that gold nanoparticles increased the number of gauche conformers and generate a conformational change within the acyl chains of phospholipids.

An important finding that could be observed was that the $\mathrm{CH}_{2}$ bending vibration modes that were located at $1469.49 \mathrm{~cm}^{-1}$ were affected by the encapsulation of clove oil into DSPC liposomal preparation as wave number was lowered to $1468.53 \mathrm{~cm}^{-1}$. This suggested the presence of ordering outcome within acyl chain packing in the gel forms of phospholipids.

The interaction between clove oil and DSPC liposomal head group was monitored by means of the $\mathrm{PO}_{2}{ }^{-}$ antisymmetric stretching band, which is positioned at $1247.72 \mathrm{~cm}^{-1}$. The wave number was moved to higher values from 1247.72 to $1249.65 \mathrm{~cm}^{-1}$ after the encapsulation of clove oil in DSPC liposomes. This suggested the absence of hydrogen bonding between clove oil and liposome head group. According to previous investigational observations lowered frequency values are exhibited an enhancement of existing hydrogen bond strengthening or in creation of new hydrogen bonding between the constituents Severcan et al. (2005). These results suggesting that clove oil was located in the interfacial region of the membrane.

In the present study analyzing data of clove oil interaction with glycerol backbone close to phospholipids head group within the interfacial region the $\mathrm{C}=\mathrm{O}$ stretching band and the wave number deviation of this band revealed shift of wave number value of $\mathrm{C}=\mathrm{O}$ group towards higher value from 1738.51 to $1739.48 \mathrm{~cm}^{-1}$ regarding liposome sample containing clove oil without any proof of hydrogen bonding formation where the amount of hydrogen-bond formation was observed in the glycerol backbone region of the DSPC molecule by alteration in the contours of the ester $\mathrm{C}=\mathrm{O}$ stretching. Analyzing these data suggesting dryness concerning these functional groups in the interfacial area of the lipid membranes. Consequently any effects in the spectra of this region can be assigned to an interaction between clove oil and the polar/a polar interfacial region of the membrane. Clove oil tends to decrease hydrogen bonding formation in the interfacial region of DSPC liposome suggesting the existence of the free carbonyl groups in the arrangement. In other words clove oil is likely to substitute some
$\mathrm{H}_{2} \mathrm{O}$ molecules from the interfacial region and lead to an increase in the number of free carbonyl groups.

When using liposomes for drug encapsulation the preparations is a mixture of entrapped and unentrapped drug fractions and science Entrapment Efficiency (EE) is the percentage of the drug that is successfully entrapped into liposomes so the first step for EE determination was to separate the entrapped drug inside the liposomes from the free one. However the process of separation and measurement of concentrations are heavy, tiring and taking long time moreover the separation procedure itself might be unsuccessfully completed. (Laouini 2012; Bano 2000). Differential scanning calorimetry (DSC) is very efficient method that does not need a separation step meanwhile it is able to access more than one parameter of liposomal encapsulation as EE, size, drug-lipid interactions and partition coefficient so that achieving quality control of liposomal encapsulation (Bakonyi et al 2017).

In the present study results of encapsulation efficiency (EE\%) of clove was $22 \%$. This may be attributed to the lipo-solublized state of the drug owing to its entrapment within multiple lipoidal domains of liposomal vesicles which enables a sustainable release of clove oil as slowly leaking out of the clove compared to its free form in the vicinity of the bacteria in culture which might explain the enhancement of the antibacterial activity by 10 times.

Differential Scanning Calorimetry (DSC) was mainly applied to determine the thermodynamics of biological macromolecules measuring phase transitions, conformational changes and temperature dependence (Chiu and Prenner 2011).

In the present study incorporation of clove oil into liposomes exhibited noticeable expansion and move to lower temperature $72^{\circ} \mathrm{C}$ of the main characteristic endothermic peak of unloaded DSPC that was existed at $79^{\circ} \mathrm{C}$ which suggested that clove oil had a significant consequence on the acyl chains of DSPC bilayer and that its presence lowered the mutual transition of the lipid acyl chains. The decreased temperature of the major DSPC transition process showed that clove oil assimilation was more likely due to the configuration of acyl chains in a disorganized and free state. The pre-transition temperature was found to be shifted from 64 to $54{ }^{\circ} \mathrm{C}$ indicating that liposomes encapsulating clove oil had a membrane fluidization effect.

\section{Conclusion}

Using liposomes as nanoscale carrier increased the efficacy of the antimicrobial activity of clove oil by 10 times than unloaded clove oil and that of tetracycline by 8 times than unloaded tetracycline when they were tested against Escherichia coli. Thus encapsulation of the antimicrobial materials into liposomes enhances their action 
and diminishes the required concentration to give its preferred actions.

\begin{abstract}
Abbreviations
DSPC: Distearoyl phosphatidylcholine; EMB: Eosin methylene blue; XLD: Xylose-Lysine Deoxycholate agar; YEGC: Yeast extract glucose chloramphenicol agar; MIC: Minimum inhibitory concentration; MBC: Minimum bactericidal concentration; CLSI: Clinical and Laboratory Standards Institute; Log DP: Logarithmic difference in population; EE: Encapsulation efficiency also for entrapment efficiency; TEM: Transmission electron microscope; FTIR: Fourier transform infrared spectroscopy; DSC: Differential scanning calorimetry; MDR: Multi drug resistant.
\end{abstract}

\section{Acknowledgements}

The authors would like to thank: Al Kasr El-Aini, Cairo University for supplying selected bacterial isolates. Central Lab at Ain Shams University for their help in examination with transmission electron microscope. Micro Analytical Center at Cairo University where Fourier Transform Infrared Spectroscopy (FTIR) spectra was done.

\section{Authors' contributions}

MH participated in and supervised the microbiological part of the practical work concerning bacterial isolation and identification, assessment of the antimicrobial activity of plant's oils by well diffusion method and Minimum Inhibitory Concentration (MIC) assay. Moreover MH is the corresponding author. She was the main writer of the manuscript and she was the one who submitted it to BNRC. MS came up with the idea of the research work, put the plan of the work and supervised the part concerning liposomal preparation and characterization. HK participated in and supervised the practical part concerning liposomal preparation and characterization. AE was responsible for doing the whole practical work, modifying, following up, writing observations and participating in writing the manuscript. $\mathrm{HH}$ was guiding, supervising the work, revising manuscript and approved it for submission. All authors read and approved the final manuscript.

\section{Funding}

No funding was received. The expenses were paid by the authors.

\section{Availability of data and materials}

The materials, the generated and analyzed data during this study are included in this published article.

\section{Ethics approval and consent to participate}

Not applicable.

\section{Consent for publication}

Not applicable.

\section{Competing interests}

The authors declare that they have no competing interests.

\section{Author details}

${ }^{1}$ Microbiology and Immunology Unit, Allergy Lab, Research Institute of Ophthalmology (RIO), 2 El Ahram Street, Giza 12557, Egypt. ${ }^{2}$ Physics Department, Faculty of Science, Helwan University, Cairo, Egypt. ${ }^{3}$ Physiological Optics Unit, Research Institute of Ophthalmology, Giza, Egypt. ${ }^{4}$ Microbiology, Botany and Microbiology Department, Faculty of Science, Helwan University, Cairo, Egypt.

Received: 20 November 2020 Accepted: 25 January 2021 Published online: 06 February 2021

\section{References}

Abalaka ME, Daniyan SY, Oyeleke SB, Adeyemo SO (2012) The antibacterial evalution of Moringa oleifera leaf extracts on selected bacterial pathogens. J Microbiol Res 2(2):1-4
Ambrosio CM, de Alencar SM, de Sousa RL, Moreno AM, Da Gloria EM (2017) Antimicrobial activity of several essential oils on pathogenic and beneficial bacteria. Ind Crops Prod 97:128-136. https://doi.org/10.1016/j.inder op.2016.11.045

Anderson M, Omri A (2004) The Effect of different lipid components on the in vitro stability and release kinetics of liposome formulations. Drug Deliv 11(1):33-39. https://doi.org/10.1080/10717540490265243

Bakathir HA, Abbas NA (2011) Detection of the antibacterial effect of Nigella Sativa ground seeds with water. Afr J Tradit Complement Altern Med 8(2):159-164. https://doi.org/10.4314/ajtcam.v8i2.63203

Bakkali F, Averbeck S, Averbeck D, Idaomar M (2008) Biological effects of essential oils-a review. Food Chem Toxicol 46(2):446-475

Bakonyi M, Berkó S, Budai-Szűcs M, Kovacs A, Csanyi E (2017) DSC for evaluating the encapsulation efficiency of lidocaine-loaded liposomes compared to the ultracentrifugation method. J Therm Anal Calorim 130:1619-1625. https://doi.org/10.1007/s10973-017-6394-1

Bano M (2000) Determination of partition coefficient by the change of main phase transition. Gen Physiol Biophys 19(3):279-293

Burt S (2004) Essential oils: their antibacterial properties and potential applications in foods - a review. Int J Food Microbiol 94(3):223-253

Chaieb K, Hajlaoui H, ZmantarT, Kahla-Nakbi AB, Rouabhia M, Mahdouani K, Bakhrouf A (2007) The chemical composition and biological activity of clove essential oil, Eugenia caryophyllata (Syzigium aromaticum L. Myrtaceae): a short review. Phytother Res 21(6):501-506

Chen Y, Li X, Liang X, Luo X, Zhang J (2016) The influence of different longcirculating materials on the pharmacokinetics of liposomal vincristine sulfate. Int J Nanomed 11:4187-4197

Chiu MH, Prenner EJ (2011) Differential scanning calorimetry: an invaluable tool for a detailed thermodynamic characterization of macromolecules and their interactions. J Pharm Bioallied Sci 3(1):39-59. https://doi. org/10.4103/0975-7406.76463

Cipolla D, Blanchard J, Gonda I (2016) Development of liposomal ciprofloxacin to treat lung infections. Pharmaceutics 8(1):6

CLSI (2012) Methods for dilution antimicrobial susceptibility tests for bacteria that grow aerobically approved standard, 9th edn. CLSI document M07A9. Clinical and Laboratory Standards Institute, Wayne

Corrêa ACNTF, Pereira PR, Paschoalin VMF (2019) Preparation and characterization of nanoliposomes for the entrapment of bioactive hydrophilic globular proteins. J. Vis. Exp. 150:e59900. https://doi.org/10.3791/59900

da Silva Malheiros P, Sant'Anna V, Micheletto YMS, da Silveira NP, Brandelli A (2011) Nanovesicle encapsulation of antimicrobial peptide P34: physicochemical characterization and mode of action on Listeria monocytogenes. J Nanopart Res 13(8):3545-3552

EIMeshad AN, Mortazavi SM, Mozafari MR (2013) Formulation and characterization of nanoliposomal 5-fluorouracil for cancer nanotherapy. J Liposome Res. https://doi.org/10.3109/08982104.2013.810644

Ghorbanzade T, Jafari SM, Akhavan S, Hadavi R (2017) Nano-encapsulation of fish oil in nano-liposomes and its application in fortification of yogurt. Food Chem 216:146-152

Granados-Chinchilla F, Villegas E, Molina A, Arias C (2016) Composition chemical fingerprinting and antimicrobial assessment of Costa Rican cultivated guavas (Psidium friedrichsthalianum (O. Berg) Nied. and Psidium guajava L.) essential oils from leaves and fruits. Nat Prod Chem Res 4(5):1000236. https://doi.org/10.4172/2329-6836.1000236

Hashemzadeh H, Javadi H, Darvishi MH (2020) Study of structural stability and formation mechanisms in DSPC and DPSM liposomes: a coarse-grained molecular dynamics simulation. Sci Rep 10:1837. https://doi.org/10.1038/ s41598-020-58730-z

Hyldgaard M, Mygind T, Meyer RL (2012) Essential oils in food preservation: mode of action, synergies, and interactions with food matrix components. Front Microbiol 3:12. https://doi.org/10.3389/fmicb.2012.00012

Ibrahim EA, Ismail MW, Kareem HS (2011) Alleviation of cisplatin-induced toxicities by encapsulation intoliposomes in the absence or presence of ginkgobiloba. J Am Sci 7(10):346-356

Jurado R, Toro-Cordova A, Ledezma-Gallegos F, Mondragon-Fuentes L, Medina LA, Perez-Rojas JM, Garcia-Lopez P (2016) Determination of liposomal Cisplatin by high-performance liquid chromatography and its application in pharmacokinetic studies. J Chromatogr Sci 54(6):1016-1021

Laouini A (2012) Preparation characterization and applications of liposomes: state of the art. J Colloid Sci Biotechnol 1:147-168 
Li M, Du C, Guo N, Teng Y, Meng X, Sun H, Li S, Yu P, Galons H (2019) Composition design and medical application of liposomes. Eur J Med Chem 164:640-653. https://doi.org/10.1016/j.ejmech.2019.01.007

Mady MM, Elshemey W (2011) Interaction of dipalmitoyl phosphatidylcholine (DPPC) liposomes and insulin. Mol Phys 109:1593-1598

Mady M, Fathy M, Youssef T, Khalil W (2011a) Biophysical characterization of gold nanoparticles-loaded liposomes. Phys Med 28(4):288-295. https:// doi.org/10.1016/j.ejmp.2011.10.001

Mady MM, Shafaa MW, Abbase ER, Fahium AH (2012) Interaction of doxorubicin and dipalmitoylphosphatidylcholine liposomes. Cell Biochem Biophys 62(3):481-486. https://doi.org/10.1007/s12013-011-9334-x

Makino K, Yamada T, Kimura M, Oka T, Ohshima H, Kondo T (1991) Temperature-and ionic strength-induced conformational changes in the lipid head group region of liposomes as suggested by zeta potential data. Biophys Chem 41(2):175-183

Masserini ME, Palestini P, Pitto M, Chigorno V, Sonnino S (2002) Preparation and use of liposomes for the study of sphingolipid segregation in membrane model systems. In: Basu SC, Basu M (eds) Liposome methods and protocols. Springer, Berlin, pp 17-27

Mohamed SJ, Amin HH, Aziz SB, Sha AM, Hassan S, Abdul Aziz JM, Rahman HS (2019) Structural characterization, antimicrobial activity and in vitro cytotoxicity effect of black seed oil. Evid-Based Complement Altern Med. https://doi.org/10.1155/2019/6515671

Mozafari M, Elmeshad A, Mortazavi S (2014) Formulation and characterization of nanoliposomal 5-fluorouracil for cancer nanotherapy. J Liposome Res 24(1):1-9

Nazzaro F, Fratianni F, De Martino L, Coppola R, De Feo V (2013) Effect of essential oils on pathogenic bacteria. Pharmaceuticals 6(12):1451-1474

Ncube N, Afolayan A, Okoh A (2008) Assessment techniques of antimicrobial properties of natural compounds of plant origin: current methods and future trends. Afr J Biotechnol 7(12):1797-1806

Nzeako BC, Al-Kharousi ZS, Al-Mahrooqui Z (2006) Antimicrobial activities of clove and thyme extracts. Sultan Qaboos Univ Med J 6(1):33-39

Oliver SP, Boor KJ, Murphy SC, Murinda SE (2009) Food safety hazards associated with consumption of raw milk. Foodborne Pathogens Dis 6(7):793-806

Paolino D, Sinha P, Fresta M, Ferrari M (2006) Drug delivery systems. In: Webster JG (ed) Encyclopedia of medical devices and instrumentation, 2nd edn. Wiley, London, pp 437-495

Pei RS, Zhou F, Ji BP, Xu J (2009) Evaluation of combined antibacterial effects of eugenol, cinnamaldehyde, thymol, and carvacrol against E. coli with an improved method. J Food Sci 74(7):379-383
Perrotta RM, Prieto MJ, Alonso SV, Chiaramoni NS (2016) DSPC liposomes improve transport of L-cysteine and reduce metabolic activity. Br Biotechnol J 12(4):1-11

British Pharmacopoeia (2010), Volume IV a microbiological assay of antibiotics. British Pharmacopoeia (BP) 2010 is the authoritative, current collection of standards for UK medicinal substances and the official source of all UK pharmaceutical quality standards

Prabuseenivasan S, Jayakumar M, Ignacimuthu S (2006) In vitro antibacterial activity of some plant essential oils. BMC Complement Altern Med 6(1):1

Safhia MM, Alama MF, Sivakumarb SM, Jabeenb A, Anwera T, Khana G, Islamc F (2014) Antibacterial spectrum of black seed oil against selected human pathogenic bacteria. J Pharm Res 8(11):1726-1728

Severcan F, Sahin I, Kazancı N (2005) Melatonin strongly interacts with zwitterionic model membranes-evidence from Fourier transform infrared spectroscopy and differential scanning calorimetry. Biochim Biophys Acta Biomembr 1668(2):215-222. https://doi.org/10.1016/j.bbame m.2004.12.009151-152

Shafaa MW, El Shazly LH, El Shazly AH, El gohary AA, El hossary GG (2011) Efficacy of topically applied liposome-bound tetracycline in the treatment of dry eye model. Vet Ophthalmol 14(1):18-25. https://doi.org/10.111 1/j.1463-5224.2010.00834.x

Smith M, Crist R, Clogston JD, McNeil SE (2017) Zeta potential: a case study of cationic, anionic, and neutral liposomes. Anal Bioanal Chem. https://doi. org/10.1007/s00216-017-0527-z

Songsong L (2011) Enhancement of the antimicrobial activity of eugenol and carvacrol against Escherichia coli O157: $\mathrm{H} 7$ by lecithin in microbiological media and food. Master's thesis, University of Tennessee

Xu JG, Liu T, Hu QP, Cao XM (2016) Chemical composition antibacterial and mechanism of action of essential oil from clove buds against Staphylococcus aureus. Molecules 21(9):1194. https://doi.org/10.3390/molecules2 1091194

Zou Y, Lee HY, Seo YC, Ahn J (2012) (2012) Enhanced antimicrobial activity of Nisin-loaded liposomal nanoparticles against food borne pathogens. J Food Sci 77(3):165-170

\section{Publisher's Note}

Springer Nature remains neutral with regard to jurisdictional claims in published maps and institutional affiliations.

\section{Submit your manuscript to a SpringerOpen ${ }^{\odot}$ journal and benefit from:}

- Convenient online submission

- Rigorous peer review

- Open access: articles freely available online

- High visibility within the field

- Retaining the copyright to your article

Submit your next manuscript at $\boldsymbol{\nabla}$ springeropen.com 